
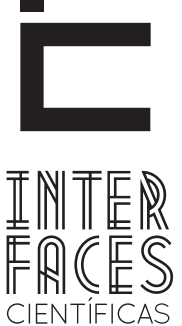

DIREITO

\title{
DOZE ANOS DE ESCRAVID̃̃O: BREVE ANÁLISE JURíDICA
}

Adriana Caetana dos Santos ${ }^{1}$
Waldimeiry Corrêa da Silva ${ }^{3}$

\section{RESUMO}

O presente artigo tem como objetivo promover a discussão crítico jurídica do filme Doze Anos de Escravidão (12 years a slave de Steve McQueen, 2014) a partir da análise da escravidão, do tráfico de pessoas, e do trabalho forçado, considerando os seus conceitos, os elementos constitutivos do tipo e a caracterização desses institutos com base nos instrumentos legais internacionais pertinentes ao assunto, bem como por meio do referencial teórico adequado. Para tanto, o estudo é realizado por meio do método hipotético-dedutivo, a partir de um visionado geral das cenas pontuais que envolvem o contexto do tráfico de pessoas para fins escravidão, permitindo um conhecimento sobre a realidade da escravatura de outrora e aproximando a discussão acerca das práticas atuais desse universo de exploração e violação dos direitos humanos. Dessa forma, chega-se a conclusão de que o filme contribui para o esclarecimento das questões que envolvem a exploração por meio da escravidão e que essa prática é algo que não ficou adstrito ao passado, sendo presente na contemporaneidade apresentando-se em moldes distintos, embora com a mesma finalidade: explorar economicamente a mão de obra humana.

\section{PALAVRAS-CHAVE}

Escravidão. Tráfico de Pessoas. Trabalho Forçado. Diretos Humanos. 


\section{ABSTRACT}

This article aims to promote legal critical discussion of the film Twelve Years a Slave (directed by Steve McQueen, 2014) from the analysis of slavery, human trafficking, and forced labor, considering their concepts of what constitutes the type and characterization of these institutions based on international legal instruments relevant to the subject, as well as through the appropriate theoretical framework. Therefore, the study is conducted through the hypothetical-deductive method, from a general point envisioned the scenes involving the context of trafficking in persons for purposes slavery, allowing knowledge about the reality of slavery of old and approaching

\section{RESUMEN}

El presente artículo objetiva suscitar la discusión crítico jurídica de la película Doce Años de Esclavitud (12 years a slave de Steve McQueen, 2014) a partir del análisis conceptual de la esclavitud, del tráfico de personas y del trabajo forzoso, considerando los elementos constitutivos del tipo y la caracterización de estos institutos con base en los instrumentos legales internacionales oportunos al tema y complementando mediante referencial teórico adecuado. Para tanto, el estudio es realizado a través del método hipotético-deductivo, a partir de un visionado general de las escenas puntuales relacionadas al contexto del tráfico de personas para fines de trabajo esclavo, permitiendo un conocimiento sobre la realidad de la esclavitud de otrora y vinculan- the discussion about current practices that universe of exploitation and violation of human rights. Thus, one comes to the conclusion that the film contributes to the clarification of the issues surrounding the exploitation through slavery and that this practice is something that was not attached to the past and present in contemporary performing in different molds, but with the same purpose: to economically exploit labor, human work.

\section{KEYWORDS}

Slavery. Human Trafficking. Forced Labor. Human Rights.

do el debate acerca de las prácticas actuales de ese universo de explotación y violación de los derechos humanos. De esa forma, se concluye que la película ayuda para el esclarecimiento de cuestiones que envuelven la explotación del trabajo por medio de la esclavitud y que esta práctica no quedó aislada en el pasado, siguiendo presente en la contemporaneidad y presentándose en moldes distintos, aunque con la misma finalidad: explotar económicamente la mano de obra humana.

\section{PALABRAS CLAVE}

Esclavitud; Tráfico de personas; Trabajo forzoso; Derechos Humanos. 


\section{CONSIDERAÇÕES INICIAIS}

0 presente estudo pretende analisar, sob a ótica jurídica, a questão do tráfico de pessoas, a escravidão e o trabalho forçado que podem ser extraídas, percebidas e comparadas a partir da compreensão do filme Twelve Yeares a Slave - Doze Anos de Escravidão (2014). A história real de Solomon Northup (1808-1863), encenada, evidencia a realidade de muitas pessoas que sobrevivem em situação de vulnerabilidade econômica, social ou cultural, indivíduos que são alvos fáceis dos aliciadores que, com a falsa promessa da busca por melhores condições de vida, traficam seres humanos como uma mercadoria para submetê-los a um regime de exploração deplorável.

A trajetória de Solomon (ator principal do enredo) descortina dar luz a discussão acerca das graves violações massivas aos direitos humanos na sociedade de outrora, num período em que a prática da escravatura era legalmente aceita pelas diferentes camadas sociais. Ela também permite uma aproximação contemporânea com a vida de milhares de pessoas que são submetidas às diferentes formas de exploração do trabalho e que vivem latente degradação da sua dignidade humana e integridade física.

O filme Doze Anos de Escravidão apresenta uma estória de escravidão por meio da exploração da força do trabalho nas grandes fazendas do passado, onde a pessoa era tratada como um bem semovente, uma coisa sobre (ou res) a qual se exercia totalmente todos os atributos do direito de propriedade, condutas estas que eram legitimadas pelo estado e que vigoravam a época (início do século XIX). Todavia, a condição do trabalho forçado e da escravização evidenciada ao longo da trama não é um problema que ficou adstrito àquela época, trata-se de um fato presente nos distintos âmbitos da exploração econômica de mercado, sejam em fazendas, grandes indústrias, no trabalho doméstico, marítimo, nas construções civis e etc.

A despeito de o filme contribuir a sensibilização sobre um processo histórico ainda latente na sociedade atual, não se pode evidenciar que o filme rea- lize um ataque a instituição da escravidão, pois não explora a dicotomia entre pessoas livres e escravas, e tampouco as relações de produção interessadas que envolve a temática.

Dada a importância da amplitude do tema ora alavancado, mediante a correlação do filme com os devidos institutos jurídicos, por meio dos instrumentos de Direito internacional, pode-se obter um esclarecimento preciso sobre os conceitos, elementos e caracterização das questões que envolvem o tráfico de pessoas e a escravidão, além de possibilitar trazer a baila como esses problemas se reproduzem na atualidade mediante as práticas análogas a escravidão ou também denominadas formas contemporâneas de escravidão.

Essa clareza é imprescindível para a promoção da cooperação, visando-se a prevenção, repressão e punição das variadas formas de violação aos direitos humanos, bem como para buscar mecanismos assistenciais as vítimas dessas práticas nocivas.

\section{A TRAMA DE "SOLOMON NORTHUP" E O TRÁFF- CO DE PESSOAS}

O filme narra à história real do tráfico e da escravização sofrida por Solomon Northup, um cidadão livre, músico violinista, que vivia uma vida agradável mesmo com certas dificuldades financeiras em Saratoga/ New York, em 1841, com sua esposa e dois filhos. Sob a falsa promessa (o engano) de trabalho para ser músico de um circo muito famoso, com boas condições salariais, de moradia e alimentação, além da garantia de custos para o retorno a sua casa para visitar a família, regularmente, a cada duas semanas, o protagonista foi atraído por aliciadores (Sr. Brown, Sr. Hamilton e Sr. Moon) que formavam parte de uma rede organizada), sendo vendido para uma rede organizada que traficava e comercializava pessoas de pele negra para serem escravizadas nos grandes latifúndios do Sul dos Estados Unidos. Já que nesse território ainda vigorava a escravidão de júris que termina em 1863, com a Proclamação de Emancipação de Abraham Lin- 
coln, realizada durante a Guerra Civil Americana (GENOVESE, 1976, p. 25).

Apesar de em 1815 ser proibido o tráfico de escravos, o contrabando continuou até o ano de 1860, enquanto que no norte crescia a campanha pela abolição.

Importante frisar que, embora o contexto temporal do filme indique um período da história em que a prática da escravidão e do tráfico negreiro fosse uma conduta aceita pela sociedade e legitimada pelos estados do Sul dos EUA, estar-se tratando da vida e da dignidade de um sujeito livre, fator esse que permite uma discussão e análise da conjectura de práticas

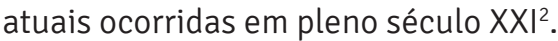

Em 1841, o tráfico negreiro e a escravatura faziam parte da realidade social no mundo, embora já se tivesse iniciado em 1815 um debate internacional com o Tratado de Paris que, de forma incipiente, tratava sobre o combate à comercialização do negro para fins de escravidão ${ }^{3}$. Na primeira metade do século XX passa-se a discutir o tráfico ${ }^{4}$, sendo que no ano de 1926 a Convenção sobre a Escravatura ${ }^{5}$, cujo teor definiu em seu artigo $1^{\circ}$ que:

O tráfico de escravos compreende todo ato de captura, aquisição ou sessão de um indivíduo com o propósito de escravizá-lo; todo ato de aquisição de um escravo com o propósito de vendê-lo ou trocá-lo; todo ato de cessão, por meio de venda ou troca, de

2. Em momento oportuno será abordado o conceito, os elementos e a características que envolvem a prática do tráfico e da escravidão contemporânea no século XXI.

3. Conforme disposto no Tratado de Londres de 1841 e em 1841 na Declaração do Congresso de Viena de 1815.

4. A maioria dos instrumentos internacionais que se ocupava do enfrentamento estava intimamente ligados a figura feminina e a exploração da prostituição: 1904 - Acordo para a Repressão do Tráfico de Mulheres Brancas; 1910 - Convênio Internacional Repressão do Tráfico de Mulheres Brancas; 1921 - Convênio Internacional para a Repressão do Tráfico de Mulheres e Crianças; 1933 - Convenção Internacional para a Supressão do Tráfico de Mulheres Maiores; 1947 - Protocolo que modifica a Convenção Internacional para a Supressão do Tráfico de Mulheres Maiores de Idade, de 1933; 1949 - Protocolo que modifica o Acordo internacional para a Repressão do Tráfico de Mulheres Brancas e o Convênio Internacional para a Repressão ao Tráfico de Mulheres Brancas. Sobre a contextualização histórica dos instrumentos legais de enfrentamento ao tráfico Verificar: ANJOS, Fernanda Alves dos; ABRÃO, Paulo. Enfrentamento ao tráfico de pessoas no Brasil: perspectivas e desafios. In: Brasil. Secretaria Nacional de Justiça. Tráfico de pessoas: uma abordagem para os direitos humanos. Brasília: Ministério da Justiça, 2013. p.217.

5. Firmada en Ginebra el 25 de septiembre de 1926. Naciones Unidas, Doc: A/Res.794 VIII. um escravo adquirido para ser vendido ou trocado; assim como em geral todo ato de comércio ou de transportes de escravos.

Complementando essa definição, a Convenção Suplementar de 1956 sobre a Abolição da Escravatura, do Tráfico de Escravos e das Instituições e Práticas Análogas à Escravatura ${ }^{6}$ conceituou o Tráficos de Escravos como "o ato de transportar ou tentar transportar escravos de um país a outro, por qualquer meio de transportes, ou a cumplicidade nesse ato", entendendo que tal prática "constituirá infração penal segundo a lei dos Estados Partes à Convenção, e as pessoas reconhecidas culpadas de tal informação serão passíveis de penas muito rigorosas" (Artigo $3^{\circ}, 1$ ).

Ao longo da história da humanidade, o tráfico de seres humanos esteve associado à escravidão ou a exploração da prostituição. Após muitos anos de discussão sobre essa temática, somente em 2000 - com o advento do Protocolo Adicional a Convenção das Nações Unidas contra a Criminalidade Organizada Transnacional relativo à Prevenção, Repressão e Punição do Tráfico de Pessoas, em especial Mulheres e Crianças (conhecido como protocolo de Palermo) - é que o tema ganha amplitude, pois se inicia o enfrentamento ao tráfico de pessoas, visando-se as diferentes modalidades de exploração com essa prática de violação grave e massiva aos Direitos Humanos. Conforme o artigo 30, alínea "a" do Protocolo de Palermo pode-se entender que:

\begin{abstract}
A expressão "tráfico de pessoas" significa o recrutamento, o transporte, a transferência, o alojamento ou o acolhimento de pessoas, recorrendo à ameaça ou uso da força ou a outras formas de coacção, ao rapto, à fraude, ao engano, ao abuso de autoridade ou à situação de vulnerabilidade ou à entrega ou aceitação de pagamentos ou benefícios para obter o consentimento de uma pessoa que tem autoridade sobre outra para fins de exploração. A exploração incluirá, no mínimo, a exploração da prostituição de outrem ou outras formas de exploração sexual, o trabalho ou serviços forçados, escravatura ou práticas similares a escravatura, a servidão ou a remoção de órgãos.
\end{abstract}

6. Convención Complementaria del Convenio sobre la Esclavitud, de 7 de septiembre de 1956, adotada mediante Resolução 608 (XXI) de 30 de abril de 1956, com entrada em vigor 30 de abril de 1957. 
A partir da definição se entende que a exploração é a fase final do tráfico de pessoas e pode ser compreendida como a finalidade desse feito. Compreendido os conceitos jurídicos de escravidão e tráfico neste artigo, focar-se-á o tráfico de pessoas. Para fins de exploração do trabalho escravo que é objeto contextual da análise do filme Doze Anos de escravidão, bem como na prática similar a escravatura correspondente ao trabalho forçado, enquanto exploração contemporânea desse fenômeno.

Como narrado no filme, Solomon Northup fora enganado sob a falsa promessa de trabalho para ser músico de um circo na cidade de Washington para onde ele foi transportado. Nessa cidade ele sofreu o sequestro e o alojamento pelo uso da força, da violência e da coação, sendo posteriormente deslocado para a cidade de Nova Orleans, onde foi escravizado, explorado por meio dos trabalhos e serviços forçados, chicoteado e manipulado como um bem móvel, uma propriedade sobre a qual se podia exercer todo e qualquer direito de dono.

Partindo desse cenário pode-se compreender o alcance da definição jurídica internacional adotada no protocolo de Palermo sobre o crime transnacional do tráfico de pessoas, pois ele permite uma visualização das etapas que compõe um processo de ações específicas dessa prática.

Segundo Inês Virgínia Prado Soares (2013, p. 80), sistematicamente, do conceito são extraídas as etapas referentes à forma, aos meios e à finalidade do tráfico humano. As ações que integram cada fase, quanto à forma como se trafica gente, são: recrutamento, transporte, transferência, alojamento ou acolhimento de pessoas (O filme retrata o transporte da vítima de Saratoga-New York para Washington); quanto aos meios usados para traficar: ameaça ou uso da força ou a outras formas de coação, ao rapto, à fraude, ao engano, ao abuso de autoridade ou à situação de vulnerabilidade ou à entrega ou aceitação de pagamentos ou benefícios para obter o consentimento de uma pessoa que tenha autoridade sobre outra (neste prisma visualiza-se o engano na falsa promessa de trabalho para obter o consentimento inicial e a poste- riori o uso da ameaça de morte, da força e da coação para mantê-lo aprisionado ${ }^{7}$ ); quanto à finalidade do tráfico: exploração de pessoas como recursos rentáveis, financeiramente, sem poder/autonomia para negociação (Solomon sofreu exploração de três fazendeiros, sendo escravizado durante 12 anos) 8 .

0 consentimento inicial do protagonista aferido na aquiescência da proposta de trabalho tornou-se irrelevante diante dos meios em que ele fora consentido e frente a toda forma de exploração sofrida ${ }^{9}$. Essa é uma observação importante, visto que normalmente a pessoa que consente na aceitação de uma proposta de trabalho, busca melhores condições de vida e jamais iria aquiescer em ser objeto de exploração de outrem, mesmo encontrando-se em situação de vulnerabilida$\mathrm{de}^{10}$, quer seja social, econômica ou cultural.

Feitas essas considerações a respeito do conceito e dos elementos constitutivos que delimitam o tráfico de pessoas na análise conjugada ao filme, passa-se a verificar no próximo tópico como se compreende juridicamente o alcance da escravidão.

\begin{abstract}
7. "A cena em que ele acorda acorrentado, deitado no chão de uma cela e é surrado com uma tabua de madeira e chicoteado por um capataz para se auto-reconhecer como um negro escravo fugitivo da cidade de Georgia, negando sua vida livre com esposas e filhos em Saratoga".

8. Nesse contexto fora realizado uma correlação dos elementos apresentados pela autora com os elementos fáticos do filme (SOARES, 2013, p. 80). 9. 0 consentimento dado pela vítima de tráfico de pessoas tendo em vista qualquer tipo de exploração descrito na alínea a do presente artigo será considerado irrelevante se tiver sido utilizado qualquer um dos meios referidos na alínea a. Embora não seja o foco de análise desse trabalho, mas vale destacar que o recrutamento, o transporte, a transferência, 0 alojamento ou o acolhimento de uma criança para fins de exploração serão considerados "tráfico de pessoas" mesmo que não envolvam nenhum dos meios referidos na definição do Protocolo. E o termo "criança" significa qualquer pessoa com idade inferior a dezoito anos (Art. $3^{\circ}$, alíneas "b", "c" e "d" do Protocolo de Palermo).

10. Vejam alguns fatores de vulnerabilidade. Do ponto de vista social e econômico, elementos como a exclusão social, a pobreza, a desigualdade social e regional e os obstáculos de acesso a oportunidades, bens e serviços, o impacto social dos modelos de desenvolvimento constituem um forte elemento de atração. Mas a discriminação de diversos grupos sociais - populações afrodescendentes, povos originários, população rural, população LGBT - geram condições de vulnerabilidade para que estas populações sejam capturadas por redes de tráfico, especialmente mulheres, crianças e adolescentes. Estes fatores culturais, reforçados pelas iniquidades de gênero, raça e geracionais e a cultura patriarcal são aspectos culturais historicamente presentes em diferentes sociedades. As demandas por serviços sexuais, a indústria do turismo, os modelos de padrões de consumo da sociedade atual, também, geram mercados desregulados que buscam lucratividade a qualquer custo (ANJOS e ABRÃO, 2013, p. 224).
\end{abstract}




\section{BREVES CONSIDERACC̄ÕES ESCRAVIDÃO TRADICIONAL}

No tópico anterior fora apresentado o conceito internacionalmente reconhecido sobre tráfico de pessoas e os elementos básicos que constituem essa ação baseados na história do filme. É importante perceber que, embora a exploração mediante a escravatura ou práticas similares a ela componha uma das finalidades do tráfico de pessoas, a escravidão e as práticas análogas à escravidão são instituições jurídicas distintas do tráfico, conforme pode ser percebido nos instrumentos legais assentados no direito internacional (CORREA DA SILVA, 2013b, p. 183-184).

A Escravidão é considerada pela doutrina como um dos temas responsáveis pela humanização dos direitos humanos onde cobra o reconhecimento da dignidade humana (CORREA, 2013). 0 processo retratado no filme 12 anos de escravidão reflete que pese o retratar um episódio ocorrido no século XIX, ainda coloca em evidencia que a complexidade e dinamismo do mundo contemporâneo ao evidenciar que, ainda que esteja proibida jurídica, social, moral e politicamente, a escravidão segue existindo na atualidade dissimulada por métodos sutis dentro da sociedade.

De acordo com a ONU entre as causas de permanência desta forma de violação massiva de direitos humanos, situa "la pobreza, la exclusión social, el analfabetismo, la ignorancia, el rápido crecimiento demográfico, la mala gestión de asuntos políticos, la corrupción, y la discriminación en todas sus formas"11. Contexto que gera uma situação de "propriedade como controle sem obrigações: controle absoluto sobre uma pessoa para explorá-la economicamente" (BALES, 2000, p. 7).

A Convenção sobre a Escravatura de 1926 define em seu art. 1.1 que a escravidão é um "estado ou condição de um indivíduo sobre o qual se exercem, total ou parcialmente, os atributos do direito de propriedade ou alguns deles". No mesmo teor a Convenção Suplementar de 1956 ratificou o enunciado, acres11. ONU, ECOSOC, Doc: E/CN.4/Sub.2/2003/L.19, 2003, par. 5². Disponível em: <http://daccess-dds-ny.un.org/doc/UNDOC/GEN/G02/150/24/PDF/ G0215024.pdf?Open Element>. centando que o "escravo" é o indivíduo em tal estado ou condição (art. $7^{\circ}$, "a”). A definição jurídica se apresenta como um critério subjetivo, já que sendo propriedade de alguém se pode dispor, como de um objeto, para desenvolver qualquer tarefa que o amo (senhor) deseje. Com esta definição aberta nos remite ao conceito histórico de escravo como 'coisa', res.

Para que se configure a escravidão não é necessário que a propriedade seja um instituto legal de um determinado ordenamento jurídico. Basta que seus atributos sejam perceptíveis no campo da realidade: o poder de domínio, subordinação que usurpe a integridade e dignidade, incluindo a mercantilizarão. Como definido pelo Tribunal Penal Internacional para a ex-Yugoslávia em $2001^{12}$, ao considerar que os atributos do direito de propriedade podem se manifestar pelo domínio que uma pessoa exerce sobre a outra, mitigando sua liberdade e integridade (CORREA DA SILVA, 2013b).

Entre as especificidades marcantes da natureza da relação na escravidão tradicional na ótica de Kelvin Bales estão: "a reivindicación de la propiedad legal; coste de adquisición elevad;, escasa rentabilidad;, falta de esclavos potenciales; relación a largo plazo; mantenimiento de los esclavos e a importancia de lãs diferencias étnicas"13 (BALES, 2000, p. 17).

A clareza da situação de domínio do dono sobre a sujeição do seu objeto - o escravo - é um fator determinante no molde da escravidão anti$\mathrm{ga}^{14}$, aquela sofrida por Solomon Northup que ao

\footnotetext{
12. TPIY, CaSo PROSECUTOR V DRAGOLJUB KUNARAC RADOMIR KOVAC AND ZORAN VUKOVIC, 12 June 2002. Disponível em: <http://www.icty. $\mathrm{org} / \mathrm{x} /$ cases/kunarac/acjug/en/kun-aj020612e.pdf>.

13. No mesmo sentido: título de propriedade, alto custo de aquisição, escassa rentabilidade, falta de escravos potenciais, relação em longo prazo (natureza da relação permanente), responsável pela manutenção dos escravos e a importância das diferenças étnicas e raciais para explicar e justificar a escravidão.

14. La esclavitud tradicional se describía como "reducción de la persona a la condición de bien semoviente"puesto que los propietarios de los esclavos podían tratarlos como parte de sus bienes, al igual que el ganado o los muebles, y venderlos o cederlos a terceros. Esas prácticas son muy infrecuentes en la actualidad y el criterio de propiedad puede eclipsar algunas de las otras características de la esclavitud que se tienen que ver con el control absoluto a que es sometida la víctima de la esclavitud por otro ser humano, y que está implícito en la fórmula de "los atributos Del derecho de propiedad o algunos de ellos" utilizada en la Convención sobre la Esclavitud (ONU, 2002, p. 20). Importante ressaltar que existem formas contemporâneas de escravidão que serão comentadas em momento oportuno.
} 
perder sua identidade de cidadão livre assume a condição de negro escravo ${ }^{15}$, chamado de Platt e pertencente a um dono (iniciou o seu trabalho escravo na fazenda do Sr. Ford com o corte de madeiras, foi vendido ao fazendeiro Sr. Epps, onde trabalhava na colheita de algodão, além de ter sido emprestado para ser explorado na colheita de cana na fazenda de um Juiz), isso no decorrer dos 12 anos em que fora violentamente explorado.

Para Orlando Paterson (2008, p. 19), “a escravidão é uma das formas de relação de dominação mais extrema, tocando o limite de poder total, do ponto de vista do senhor, e de impotência total, do ponto de vista do escravo". O autor também apresenta as facetas que podem envolver essa relação, o que corrobora para elucidar as especificidades que envolvem a escravidão, são elas:

\begin{abstract}
A primeira é a social que envolve o uso ou a ameaça da violência no controle de uma pessoa por outra. A segunda é a faceta psicológica da influência, a capacidade de persuadir outra pessoa a fim de mudar o modo com ela concebe seus interesses e circunstâncias. A terceira é a faceta cultural da autoridade, os meios de se transformar força em direito, e obediência em dever. (PATERSON, 2008, p. 19-20).
\end{abstract}

Essas três formas de poder de manipulação sobre o outro são perceptíveis nas violações sofridas por Solomon em algumas passagens do filme: a social, evidenciada no controle, por meio da violência física sofrida com os açoites de chicotes ${ }^{16}$ e a constante ameaça de morte se tentasse fugir; a psicológica, manifestada mediante o canto da música juntamente com o seu mestre (o capataz), como uma forma de persuadir o escravo a, sequer, despertar o

15. 0 canto de lamuria de Solomon junto aos demais escravos, em volta do corpo enterrado, é um momento marcante, pois revela a impressão da sua identificação do negro escravizado. Sobre o tema a escritora afro estadunidense Toni Morrison dedica una minuciosa análise da influencia da música como forma de protesta social en Song for a Solomon (1977).

16. 0 chicote não era apenas um método de punição. Era um dispositivo usado conscientemente para lembrar aos escravos que eles eram escravos; era uma forma crucial de controle social, sobretudo se lembrarmos que era muito difícil aos escravos fugirem com sucesso (GEORGE APUD PATTERSON, 2008, p. 22) interesse de fugir ${ }^{17}$; a cultural, por sua vez, exercida na relação do direito do senhor em poder vender, trocar, emprestar o seu escravo, e este em apenas obedecer, sem poder reivindicar direitos, já que se encontra na condição de objeto diante de si mesmo e de toda sociedade.

Neste sentido, Patterson também argumenta que todas as relações humanas são estruturadas e definidas pelo poder que uma pessoa exerce sobre outra, variando a diferentes níveis e aspectos, podendo incluso se recíprocos. No caso da escravidão, a relação de poder de um indivíduo sobre outro não é mutua, e sim, extrema, já que apenas um polo da relação exerce esse poder, enquanto o outro se encontro subordinado sob um total domínio ou submissão. E poder, seria a oportunidade existente dentro de uma relação social que permite uma pessoa impor sua vontade, ainda que diante de uma situação de resistência (como apresentada no filme) (PATTERSON, 2009).

A escravidão conflui no seu aspecto coercitivo, enquanto processo de exploração e exclusão, acaba por individualizar o sujeito em uma condição de inferioridade, tornando-o impotente em relação a outro indivíduo. Geralmente isso é um reflexo do padrão de desenraizamento do sujeito com sua origem, sua história.

Esse aspecto é refletido na trama quando Solomon Northup perde sua identidade, nega ou omite, diante dos Senhores de escravo, a sua condição de sujeito livre, sua origem, seus saberes educacionais e esse contexto de desligamento com sua história traz consigo a carga negativa da desonra por toda violência sofrida na sua integridade física e moral, decorrente de ter chegado a tal estado devido à crença de que se estaria a buscar melhores condições de vida ${ }^{18}$. Esta questão ficou evidente na cena final do filme com o pedido de desculpas a família, quando do seu retorno para casa.

Até aqui se tratou dos aspectos jurídico do tráfico e da escravidão antiga que estão envolvidas no filme Doze Anos de Escravidão. Sem dúvida o trabalho escravo dos negros no mundo é uma das maiores explorações eco-

17. Trecho da música: “corra, negro, corra, pois o caçador te pegará, corra, negro, corra bastante é melhor desaparecer, pois o caçador te pegará”. 18. Para Orlando Patterson (2008, p. 34) “a escravidão é a dominação permanente e violenta de pessoas desenraizadas e geralmente desonradas". 
nômicas na história da humanidade que provocou grave violação aos direitos humanos. Diante das questões abordadas, de que forma se podem vincular à trama do filme as formas contemporâneas de escravidão?

Partindo do contexto que a escravização ocorreu com um cidadão livre e que todo seu processo de exploração estava adstrito a força produtiva do trabalho nas grandes fazendas, pode-se analisar e compreender como esse assunto é tratado hoje pelo direito nos instrumentos internacionais relativos ao trabalho forçado.

\section{TRABALHO FORÇADO E SUA CORRELAÇ̃̃̃O COM A ESCRAVIDÃO CONTEMPORÂNEA}

Bem verdade que a forma tradicionalmente conhecida da escravidão já não faz parte da realidade atual, porém não significa dizer que essa prática tenha sido totalmente erradicada abolida, pois vários fatores contribuem para sua existência ${ }^{19}$, mas com moldes distintos da escravidão antiga. A escravidão contemporânea evita a propriedade legal sobre o escravo, tem custo de aquisição moderado e elevadíssima rentabilidade, pois existe no mundo uma "massa humana em situação de vulnerabilidade que gera um excesso de escravos potenciais com relação de exploração em curto prazo, podendo haver a expulsão de escravos, além de ser nula a importância das diferenças étnicas ou raciais ${ }^{20}$ (BALES, 2000, p. 17).

Entre as várias práticas contemporâneas de escravidão ou formas análogas à escravidão ${ }^{21}$ encontra-se

19. Para Kevin Bales (2000, p. 15) a nueva esclavitud é reflexo "La corrupición política, unida al espetacular crecimento de la populación y a su continuo empobrecimiento, há dado lugar a nueva esclavitud". Pode-se acrescentar a esses fatores o modelo capitalista enveredado no mundo pós- guerra em que a corrida por produtividade passa a constituir o foco das nações, a globalização como facilitadora dessa exploração a nível global e etc. 20. A nueva esclavitud se resume desta manera: "evitación de la propiedad legal; coste de adquisición muy moderado; elevadíssima rentabilidad; excesso de esclavos potenciales; relación a corto plazo; expulsión de los esclavos; nula importância de lãs diferencias étnicas” (BALES, 2000, p. 17). 21. Entre as instituições ou práticas análogas à escravidão encontram-se: a) a servidão por dividas, isto é, o estado ou a condição resultante do fato de que um devedor se haja comprometido a fornecer, em garantia de uma dívida, seus serviços pessoais ou os de alguém sobre o qual tenha autoridade, se o valor desses serviços não for equitativamente avaliado no ato da liquidação de dívida ou se a duração desses serviços não for limitada nem o trabalho forçado. Segundo a OIT (2005, p. 26) a escravidão é uma forma de trabalho forçado que implica o domínio absoluto de uma pessoa por outra ou, às vezes, de um grupo de pessoas por outro grupo social. $E$, este é definido nos termos do Convênio $n^{0} 29$ de $1930^{22}$ como "todo trabalho ou serviço exigido de uma pessoa sob a ameaça de sanção e para o qual ela não tiver se oferecido espontaneamente" (OIT, 1930, artigo 2.1). De acordo com José Claudio Monteiro de Brito (2013, p. 43), o trabalho forçado define-se como "o trabalho que for prestado por trabalhador a tomador de serviço em regime obrigatório, quando não decorrer da livre vontade do primeiro, quando a obrigatoriedade for consequência, por qualquer circunstância ou anulação de sua vontade".

Nestes termos, caracteriza-se o trabalho forçado como uma espécie de forma análoga a escravidão observando-se: “1) a existência de uma relação de trabalho entre os sujeito ativo (tomador do serviço) e passivo (trabalhador); 2) e o fato de o trabalho ser prestado de forma compulsório, independente da vontade do trabalhador ou anulação de sua vontade por qualquer circunstância que assim o determine" (BRITO, 2013, p. 43).

O conceito apresentado pela OIT (2005, p. 14) comporta dois elementos básicos: i) trabalho ou serviço imposto sob ameaça de punição; ii) e aquele executado involuntariamente. De acordo com a professora Waldimeiry Corrêa da Silva há uma abordagem que:

sua natureza definida; b) a servidão, isto é, a condição de qualquer um que seja obrigado pela lei, pelo costume ou por um acordo, a viver e trabalhar numa terra pertencente a outra pessoa e a fornecer a essa outra pessoa, contra remuneração ou gratuitamente, determinados serviços, sem poder mudar sua condição; c) Toda instituição ou prática em virtude da qual: I - uma mulher é, sem que tenha o direito de recusa prometida ou dada em casamento, mediante remuneração em dinheiro ou espécie entregue a seus país, tutor, família ou a qualquer outra pessoa ou grupo de pessoas, II - o marido de uma mulher, a família ou o clã deste tem o direito de cedê-la a um terceiro, a título oneroso ou não, III - a mulher pode, por morte do marido ser transmitida por sucessão a outra pessoa;

d) toda instituição ou prática em virtude da qual uma criança ou um adolescente de menos de dezoito anos é entregue, quer por seu pais ou um deles, quer por seu tutor, a um terceiro, mediante remuneração ou sem ela, com o fim da exploração da pessoa ou do trabalho da referida criança ou adolescente (Art. $1^{\circ}$ da Convenção Suplementar de 1956).

22. OIT. Convênio $n^{0} 29$ relativo ao trabalho forçado ou obrigatório da OIT, adotado em Genebra pela Conferencia Geral da Organização Internacional do Trabalho (sessao14) em de 28 de junho de 1930. 
O trabalho forçado geralmente ocorre mediante uma falsa promessa de emprego, que ilude a suposta vítima com um trabalho em boas condições e remuneração que logo não são cumpridas. Além de, em muitos casos, os trabalhadores nem serem remunerados, também são submetidos à violência física e psicológica, e ainda sofrem restrições de liberdade e movimento. (JORDAN, 2011, p. 5 APUD SILVA, 2013a, p. 435).

Neste prisma, pode-se aproximar a história de escravização vivida por Solomon Northup no filme à forma atual de escravidão por meio do trabalho forçado. Isso porque a trama é clara ao mostrar que ele acreditou na falsa promessa de emprego e o quanto sofreu durante 12 anos, não só as ameaças, mas propriamente a sanção por meio dos açoites de chicotes, além das constantes humilhações. E o outro elemento que se perfaz na não aceitação voluntária daquelas condições de trabalho (exploratório, degradante, sem salário, sem descanso e etc.). Conforme estudo realizado pela OIT referente à "Aliança Global Sobre o Trabalho Forçado" a ameaça de sanção e a involuntariedade do exercício do trabalho podem ser configurados da seguinte forma:

Falta de consentimento (natureza involuntária do trabalho) ("itinerário" do trabalho forçado): escravidão por nascimento ou por descendência de escravo / servidão por dívida; rapto ou sequestro,venda de pessoa a outra, confinamento no local de trabalho - em prisão ou em cárcere privado; coação psicológica, isto é, ordem para trabalhar, apoiada em ameaça real de punição por desobediência; dívida induzida (por falsificação de contas, preços inflacionados, redução do valor de bens ou serviços produzidos,taxas de juros exorbitantes, etc.); engano ou falsas promessas sobre tipos e condições de trabalho; retenção ou não pagamento de salários, retenção de documentos de identidade ou de pertences pessoais de valor.

Ameaça de punição (meios de manter alguém em regime de trabalho forçado): violência física contra o trabalhador ou sua família ou pessoas próximas; violência sexual; (Ameaça de) represálias sobrenaturais; prisão ou confinamento; punições financeiras; denúncia a autoridades (polícia, autoridades de imigração, etc.) e deportação; demissão do emprego atual; exclusão de empregos futuros; exclusão da comunidade e da vida social; supressão de direitos ou privilégios; privação de alimento, habitação ou de outras necessidades; mudança para condições de trabalho ainda piores; perda de status social. (OIT, 2005, p. 14).

O parâmetro hodierno da globalização da escravidão que permite o Deslocamento do ser humano, que será colocado em situação análoga à da escravidão do "escravo" não tem como escopo a apropriação absoluta da pessoa para a exploração como ocorria outrora (na época em que o filme retrata, mas, sim, visa apenas à exploração do valor econômico da mão de obra que o indivíduo possa oferecer, seja por meio de vantagens financeiras ilícitas, contratos laborais fraudulentos, nas brechas legais ou etc.

0 trabalho forçado representa grave violação de direitos e restrição da liberdade humana, conforme definido nas convenções da OIT sobre a matéria e em outros instrumentos internacionais correlatos sobre escravidão e as práticas análogas à escravidão. Dessa maneira, o trabalho forçado não pode simplesmente ser equiparado a baixos salários ou a más condições de trabalho. Tampouco cobre situações de mera necessidade econômica (OIT, 2005, p. 13).

Assim, uma perspectiva essencial de combate ao trabalho forçado é que essa prática seja tratada como um tipo injusto grave quando da sua imposição ile$\mathrm{gal}^{23}$, devendo ser punida como delito penal e será dever de todo Estado-membro que ratificar a Convenção assegurar que as penalidades impostas pela lei sejam realmente adequadas e rigorosamente aplicadas ${ }^{24}$. Para isso, entende-se que a clareza conceitual e a elucidação dos elementos que compõe essa conduta agressiva aos direitos é fator determinante para a promoção do seu enfretamento.

No caso do filme, os homens responsáveis pelo tráfico e pela escravidão de Solomon Northup (cidadão livre), apesar de levados a julgamento e após longos anos de procedimentos legais, nenhum sofreu a devida condenação, como retrata o filme.

23. Vale ressaltar que os instrumentos legais da OIT não proíbem absolutamente o trabalho forçado, pois abre espaço para exceções em conformidade com os artigos $1^{\circ}, 10$ e 11 da Convenção $n^{0} 29$ da OIT.

24. Ideias apresentadas no parágrafo 29 do texto sobre "A Aliança Global sobre o Trabalho Forçado", OIT, 2005. 


\section{CONSIDERACÕ̃ES FINAIS}

A escravidão, como problema social, econômico e político, vem sendo combatida há quase dois séculos ${ }^{25}$. Ainda que para alguns possa parecer um tema solucionado. Após sua abolição, observamos que na atualidade o tema cobra cada vez mais importância, devido à proliferação das formas contemporâneas de escravidão, evidenciando a ineficácia para sua erradicação. Ainda que distintos instrumentos e mecanismos de proteção de direitos humanos busquem salvaguardar a dignidade humana, observa-se que as causas produtoras da escravidão contemporânea são conhecidas e de difícil superação por se tratar de corrupção política, adicionada ao crescimento populacional (sobretudo em zonas mais pobres economicamente), que gera uma massa humana excluída dos benefícios da globalização econômica e susceptíveis a tornar-se "escravos potenciais" (BALES, 2001, p. 15).

Ou como definido por Bauman como estranhos (2008, p. 61-62), que são os excluídos economicamente por fazer referência aos despossuídos dentro da sociedade de mercado, já que esta os valora por seu valor como mercadoria. Portanto, os despossuídos são pessoas sem valor de mercado, não consumidores que se situam a margem, são desnecessários, indesejados e desamparados.

Com base na análise do filme Doze Anos de Escravidão conjugada as questões jurídicas que envolvem a trama, pôde-se perceber que o filme contribui para o esclarecimento das questões que envolvem a exploração por meio da escravidão e que essa prática é algo que não ficou adstrito ao passado, sendo presente na contemporaneidade com moldes distintos, embora com a mesma finalidade: explorar economicamente a mão de obra da pessoa humana.

Diante da ficção relatada pelo filme e a realidade persistente das formas contemporâneas de escravidão, se faz necessário avaliar sobre os dogmas e categorias jurídicas anteriores (instituições jurídicas 25. Levando em consideração que o primeiro documento histórico a combater a escravidão foi a "Declaración Relativa a la Abolición Universal de la Trata de esclavos”, de 8 de fevereiro de 1815 (DECLARATION..., 1815). de escravidão, tráfico de pessoas e trabalho escravo) para vislumbrar saídas que respondam ao interesse da proteção da dignidade humana como categoria indivisível. De acordo com este axioma, a teoria crítica dos direitos humanos fomenta a lógica da humanização necessária. Ou seja, centra o ser humano como referente da emancipação e liberdade, respondendo ao direito de combater contra a subvaloração das pessoas e as tramas sociais que forjam para seguir coexistindo (SANCHEZ RUBIO, 2011).

Como se buscou evidenciar, diante de toda a análise é possível entender claramente que o tráfico de pessoas, a escravidão e o trabalho forçado constituem instituições jurídicas distintas e que cada um desses institutos possuem um tratamento jurídico diferenciado nos instrumentos internacionais de direito. Sem dúvida, a clareza quanto ao conceito e os elementos que envolvem essas práticas permitem uma reflexão sobre essas questões, além de promover uma sensibilização para o reconhecimento diante da sua ocorrência. Isso, sem dúvida, facilita à promoção do enfrentamento a essas práticas que envolvem a exploração dos seres humanos, seja para prevenir, reprimir, sancionar, ou ainda, prestar assistência.

\section{REFERÊNCIAS}

ANJOS, Fernanda Alves dos; ABRÃO, Paulo. Enfrentamento ao tráfico de pessoas no Brasil: perspectivas e desafios. In: Brasil. Secretaria Nacional de Justiça.

Tráfico de pessoas: uma abordagem para os direitos humanos. Brasília: Ministério da Justiça, 2013. p.215-233.

\section{BALES, Kevin. La nueva esclavitud en la economia}

global. Madrid: Siglo Veintiuno, 2000.

BRASIL. Decreto $\mathbf{n}^{0}$ 5017, de 12 de março de 2004. Promulga o Protocolo Adicional à Convenção das Nações Unidas contra o Crime Organizado Transnacional Relativo à Prevenção, Repressão e Punição do Tráfico de Pessoas, em Especial Mulheres e Crianças. 
BRITO FILHO, José Claudio Monteiro. Trabalho escravo: caracterização jurídica dos modos típicos de execução. In: REZENDE, Ricardo; PRADO, Adonia Antunes; GALVÃO, Edna Maria (Org.). Privação de liberdade ou atentado à dignidade: escravidão contemporânea. Rio de Janeiro: Mauad X, 2013.

CORRÊA DA SILVA. W. Tráfico de pessoas em sinergia negativa com o trabalho forcado: uma forma contemporânea de escravidão. In: REZENDE, Ricardo; PRADO, Adonia Antunes; GALVÃO, Edna Maria (Org.). Privação de liberdade ou atentado à dignidade: escravidão contemporânea. Rio de Janeiro: Mauad X, $2013 a$.

CORREA da SILVA, Waldimeir; GOES, K. D. G. E. A realidade multifacetada do tráfico de pessoas. In: Paulo César Corrêa Borges. (Org.). Tráfico de pessoas para exploração sexual: prostituição e trabalho sexual escravo. Sao Paulo: Cultura Acadêmica (UNESP), v.1, 2013b. p.183-198.

DECLARATION Relative to the Universal Abolition of the Slave Trade, 8 February 1815, Consolidated Treaty Series, v.63, n.473.

GENOVESE, Eugene. A Economia política da escravidão. Rio de Janeiro: Pallas, 1976.

OHCHR. La abolición de la esclavitud y sus formas contemporáneas. HR/PUB/02/4. ONU: NY/Ginebras, 2002.
ORGANIZAÇÃO DAS NAÇÕES UNIDAS. Convenção sobre a escravatura de 1926. Genebra, 1926.

ORGANIZAÇÃO DAS NAÇÕES UNIDAS. Convenção suplementar sobre a abolição da escravatura, do tráfego de escravos e das instituições e práticas análogas à escravatura. Genebra, 1956.

ORGANIZAÇÃO INTERNACIONAL DO TRABALHO. Convención $n^{\circ} 29$ sobre trabajo forzoso u obligatorio de la OIT. Adoptado en La conferencia General de La Organización Internacional del trabajo (sesión 14). Convenio relativo al trabajo forzoso u obligatorio, del 28 de junio de 1930, Genebra.

ORGANIZAÇÃO INTERNACIONAL DO TRABALHO. Uma aliança global contra o trabalho forçado. Genebra: OIT, 2005.

PATTERSON, Orlando. Escravidão e morte social: um estudo comparativo. São Paulo: USP, 2008.

SANCHEZ RUBIO, David. Encantos y desencantos de los derechos humanos. Barcelona: Icaria, 2011.

SOARES, Inês Virgínia Prado. Enfrentamento ao tráfico de pessoas sob a ótica dos direitos humanos no Brasil. In: Brasil. Secretaria Nacional de Justiça. Tráfico de pessoas: uma abordagem para os direitos humanos. Brasília: Ministério da Justiça, 2013. p.75-103. 
1. Advogada inscrita na seccional $\mathrm{OAB} / \mathrm{SE}$. Mestranda no Programa de Direitos Humanos da Universidade Tiradentes - UNIT/SE. Integrante nos diretórios de grupo de pesquisa vinculado ao CNPq: Acesso à justiça, direitos humanos e resolução de conflitos; Política Criminal e Direitos Humanos: efetividade e garantias processuais. E-mail: drica_caetana@hotmail.com 2. Doutora em Direito internacional e Relações internacionais. Professora

Recebido em: 10 de Setembro 2015

Avaliado em: 12 de Setembro de 2015 Aceito em: 30 de Setembro de 2015
Adjunta da Universidad Loyola Andalucía. Conselheira do Comitê Nacional de Enfrentamento ao Tráfico de Pessoas (CONATRAP/SNJ/MJ). E-mail: drica_caetana@hotmail.com 